\title{
The cAMP-Protein Kinase A Signal Transduction Pathway Modulates Ethanol Consumption and Sedative Effects of Ethanol
}

\author{
Gary Wand, ${ }^{1,2}$ Michael Levine, ${ }^{1,3}$ Larry Zweifel, ${ }^{1}$ William Schwindinger, ${ }^{5}$ and Ted Abel ${ }^{4}$ \\ Departments of ${ }^{1}$ Medicine, ${ }^{2}$ Psychiatry, and ${ }^{3}$ Pediatrics, The Johns Hopkins University School of Medicine, Baltimore, \\ Maryland 21205, ${ }^{4}$ Department of Biology, University of Pennsylvania, Philadelphia, Pennsylvania 19104, and ${ }^{5}$ Weis \\ Center for Research, The Geisinger Clinic, Danbury, Pennsylvania 17822
}

Ethanol and other drugs of abuse modulate cAMP-PKA signaling within the mesolimbic reward pathway. To understand the role of the CAMP-PKA signal transduction in mediating the effects of ethanol, we have studied ethanol consumption and the sedative effects of ethanol in three lines of genetically modified mice. We report that mice with the targeted disruption of one Gs $\alpha$ allele as well as mice with reduced neuronal PKA activity have decreased alcohol consumption compared with their wild-type littermates. Genetic reduction of cAMP-PKA signaling also makes mice more sensitive to the sedative effects

The cAMP-PKA signal transduction pathway is a ubiquitous cascade that modulates numerous cellular events within neurons (Abel and Kandel, 1998; Self et al., 1998). The stimulatory G-protein Gs couples and amplifies ligand-induced signals transmitted from receptors to multiple isoforms of adenylyl cyclase. We have previously shown that alcohol-preferring rats have increased adenylyl cyclase activity and increased expression of the $\alpha$ subunit of Gs $(\mathrm{Gs} \alpha)$ in mesolimbic regions of the brain (e.g., nucleus accumbens and ventral tegmental area) compared with alcohol-nonpreferring rats (Froehlich and Wand, 1997). Levels of Gs $\alpha$ are similarly increased in blood cell membranes from humans at increased risk for alcoholism (Wand et al., 1994). In addition, a series of studies have identified biochemical abnormalities in this pathway in erythrocyte, lymphocyte, and platelet membranes derived from alcoholic persons (Tabakoff et al., 1988; Gordon et al., 1991; Waltman et al., 1993; Parsian et al., 1996; Menninger et al., 1998). Ethanol and other drugs of abuse modulate cAMP-PKA signaling within the mesolimbic reward pathway (Hoffman and Tabakoff, 1990; Self et al., 1998; Spanagel and Weiss, 1999). Because the magnitude of adenylyl cyclase activity as well as vulnerability to alcoholism are both influenced by strong genetic determinants (Devor et al., 1991; Foroud and Li,

\footnotetext{
Received March 13, 2001; revised April 18, 2001; accepted April 19, 2001.

This work was supported by National Institutes of Health (NIH) Grant AA09000 and the Lattman Foundation (G.W.); by NIH Grants AG18199 and MH60244, the Whitehall Foundation, the University of Pennsylvania Research Foundation, and a Young Investigator Award from the Mental Retardation and Developmental Disabilities Research Center at Children's Hospital of Philadelphia (HD26979) (T.A.); and by NIH Grant DK18213 (M.L). T.A. is also a John Merck Scholar. We thank Haejin Kim for her technical support, Arati Sadalge for her assistance with the in situ hybridization experiment, Alan Young for his help with dissections for the adenylyl cyclase assays in Gs $\alpha$ Q227L mice, and Dr. Xiaoju Yang for running adenylyl cyclase assays in this mouse line.

Correspondence should be addressed to Dr. Gary Wand, Professor of Medicine and Psychiatry, The Johns Hopkins University School of Medicine, Ross Research Building, Room 863, 720 Rutland Avenue, Baltimore, MD 21205. E-mail: gwand@welch.jhu.edu.

Copyright (C) 2001 Society for Neuroscience $\quad 0270-6474 / 01 / 215297-07 \$ 15.00 / 0$
}

of ethanol, although plasma ethanol concentrations are unaffected. In contrast, mice with increased adenylyl cyclase activity resulting from the transgenic expression of a constitutively active form of $\mathrm{Gs} \alpha$ in neurons within the forebrain are less sensitive to the sedative effects of ethanol. Thus, the CAMPPKA signal transduction pathway is critical in modulating sensitivity to the sedative effects of ethanol as well as influencing alcohol consumption.

Key words: alcohol; sedation; adenylyl cyclase; protein kinase A; cAMP; alcoholism
1999), it is conceivable that genes controlling cAMP-PKA signaling in the mesolimbic reward pathway play an important role in determining genetic vulnerability for alcoholism.

Compared with the offspring of nonalcohol-dependent parents, the offspring of alcoholics have a 4- to 10 -fold increased probability of developing alcoholism during their teenage years and adulthood (Schuckit, 1994, 2000). Human studies of "at risk" individuals have established a premorbid phenotype characterized by increased drug liking and decreased sensitivity to sedative effects of alcohol (Schuckit, 2000). Therefore, we hypothesized that genetically altering the neuronal cAMP-PKA signaling pathway would modulate alcohol drinking behavior as well as sensitivity to the sedative effects of alcohol.

\section{MATERIALS AND METHODS}

Animals. The Gnas $(-/+)$ mutation was generated by homologous recombination in J1 embryonic stem (ES) cells (Schwindinger et al., 1997). One targeted ES cell clone that was introduced into C57BL/6J embryos resulted in viable, fertile, male chimeras that transmitted the targeted Gnas allele to their progeny. The Gnas $(-/+)$ was maintained on three backgrounds: C57BL/6J, 129SvEv, and 129SvEv xCD1. The Gnas $(-/+)$ mutation carried in $\mathrm{C} 57 \mathrm{BL} / 6$ background was generated by breeding chimeras to $\mathrm{C} 57 \mathrm{BL} / 6 \mathrm{~J}$, which were then back-crossed with $\mathrm{C} 57 \mathrm{BL} / 6 \mathrm{~J}$ mice (Taconic, Germantown, NY). Similarly, Gnas $(-/+)$ carried in 129SvEv background were generated by breeding chimeras to $129 \mathrm{SvEvs}$ (Taconic), which were then back-crossed with 129SvEV mice. Gnas $(-/+)$ carried in $129 \mathrm{SvEv} \times \mathrm{CD} 1$ background was generated by breeding Gnas $(-/+)$ carried in 129SvEv background with CD1s (The Jackson Laboratory, Bar Harbor, ME) and then inbreeding for subsequent generations. Gnas $(-/+)$ mice were at N3-N7 for this study and genotyped as described (Schwindinger et al., 1997). Because of genetic imprinting of the Gnas gene (Hayward et al., 1998), only mice with maternal inheritance of the disrupted allele were used in these studies. The R(AB) and Gs $\alpha$ Q227L transgenes are maintained in a hemizygous state on a C57BL/6J background (N7-N9) and genotyped as described (Abel et al., 1997, 1998).

All mice lines develop normally and are fertile. Colonies and experimental rooms were maintained at $22^{\circ} \mathrm{C}$ with a $12 \mathrm{hr}$ light/dark cycle, and testing occurred during hours 2-6 of the light phase. Both males and females were used for the studies, and no gender differences were noted. 
Mice were between the ages of 2 and 4 months at the time of testing. Animal care and handling procedures were in accordance with institutional and National Institutes of Health guidelines.

Preference test. Mice were housed individually and habituated to their home cage for 1 week. During this period mice were allowed equal access to two, $50 \mathrm{ml}$ feeding tubes (Bio-Serv) containing water. Mice were then offered $3 \%$ ethanol $(\mathrm{v} / \mathrm{v})$ versus water for $3 \mathrm{~d}$. Tube positions were changed every day to control for position preferences. Immediately after exposure to $3 \%$ ethanol, choice between $6 \%$ ethanol and water was offered for $3 \mathrm{~d}, 10 \%$ versus water for $3 \mathrm{~d}$, and finally $20 \%$ ethanol versus water for $3 \mathrm{~d}$. Body weight and food consumption were averaged over each $3 \mathrm{~d}$ trial. Ethanol consumption was measured as total volume consumed per trial or grams of ethanol per kilogram to correct for differences in body weight. Ethanol preference is defined as volume of ethanol consumed divided by total volume consumed (ethanol + water). After a 1 week hiatus, sucrose and quinine preferences were obtained in a similar manner on the same mice with the substitution of ethanol with either 1.7 and $4.5 \%$ sucrose or 0.015 and $0.03 \mathrm{~mm}$ quinine hemisulfate. Two-way, $2 \times 2$ (genotype $\times$ concentration) repeated-measure ANOVAs were used for statistical analysis for all preference studies.

Test of sensitivity for ethanol-induced sedation. Mice were given an intraperitoneal injection of $3.5 \mathrm{gm} / \mathrm{kg}$ ethanol $(20 \% \mathrm{v} / \mathrm{v}$ in $0.9 \%$ saline $)$ and then placed on their backs in a V-shaped trough $(13 \times 10 \mathrm{~cm})$. Loss of righting reflex is defined as the time interval between injection and loss of ability to stand on three of four paws. Gain of righting reflex is defined as the time interval between loss of righting reflex and regaining of righting reflex. Ethanol-induced sedation is expressed as sleep time (time to gain righting reflex minus time to loss of righting reflex). Data were analyzed by $t$ test.

Plasma ethanol concentration. We took $\sim 20 \mu \mathrm{l}$ of tail blood samples at the indicated time points after injection. Samples were microcentrifuged $20 \mathrm{~min}(14,000 \mathrm{rpm})$ at $4^{\circ} \mathrm{C}$ and analyzed immediately. Plasma ethanol was determined by an ADH/NADH assay (Sigma Diagnostic) following manufacturer specifications. Two-way, $2 \times 2$ (genotype $\times$ time) repeated-measure ANOVAs were used for statistical analysis.

Adenylyl cyclase activity and immunoblots. Membranes were prepared, and adenylyl cyclase assays and immunoblots were performed as described (Froehlich and Wand, 1997). G-protein signals were densitized using a Personal Densitometer (Molecular Dynamics, Sunnyvale, CA), and Gs $\alpha$ expression was normalized to levels of Go $\alpha$, which did not differ by genotype. Densitometric data were analyzed by $t$ test.

In situ hybridization. Mouse brains were dissected and rapidly frozen in Tissue-Tek embedding medium. Coronal sections $(20 \mu \mathrm{M})$ were fixed and hybridized to a transgene-specific $\left[\alpha{ }^{35} \mathrm{~S}\right] \mathrm{dATP}$-labeled oligonucleotide probe as described (Abel et al., 1997). Slides were exposed for 4 weeks to Kodak (Eastman Kodak, Rochester, NY) Biomax MR autoradiographic film.

$\left[{ }^{3} \mathrm{H}\right]$ Ro15-1788 binding to brain membranes were performed as previously described (Hodge et al., 1999).

\section{RESULTS}

To begin studying the functional relationship between Gs $\alpha$ and ethanol consumption and sensitivity, we examined mice with heterozygous inactivation of the Gnas gene encoding Gs $\alpha$ [Gnas $(-/+)$ mice] that was generated by disruption of exon 1 (Schwindinger et al., 1997). Quantitative immunoblot studies showed that levels of Gs $\alpha$ in Gnas $(-/+)$ mice were significantly reduced relative to wild-type (WT) levels in multiple brain regions, including the nucleus accumbens (Fig. 1a), hypothalamus $(100 \pm 18$ vs $61 \pm 5 ; p<0.02)$, hippocampus $(100 \pm 16$ vs $53 \pm$ $7 ; p<0.01)$, and cerebellum $(100 \pm 14$ vs $62 \pm 11 ; p<0.05)$. Nissl-stained as well as hematoxylin- and eosin-stained sagittal sections of brains from Gnas $(-/+)$ mice showed no gross anatomical abnormalities within the hypothalamus or other regions (data not shown). Figure $1 b$ shows that adenylyl cyclase activity in nucleus accumbens membranes from Gnas $(-/+)$ mice is significantly reduced relative to WT membranes when stimulated with fluoroaluminate (AlF) and guanosine triphosphate (GTP). Table 1 shows reduced AlF-stimulated adenylyl cyclase activity observed in membranes prepared from Gnas $(-/+)$ hypothalamus (30\% reduction), cerebellum (23\% reduction), hippocampus
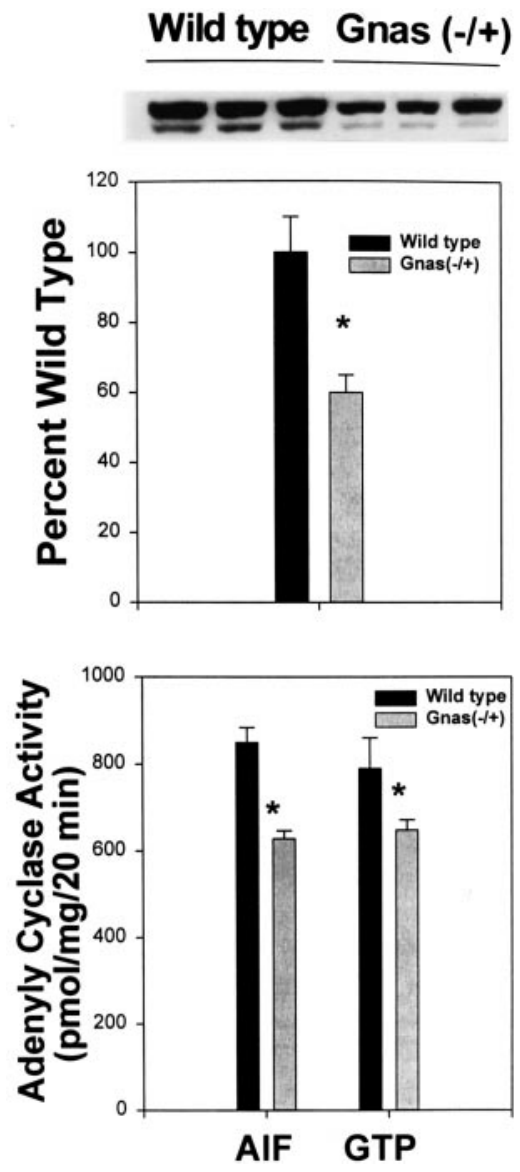

Figure 1. Comparison of nucleus accumbens Gs $\alpha$ protein levels and adenylyl cyclase activity in Gnas $(-/+)$ and wild-type littermates in $\mathrm{C} 57 \mathrm{BL} / 6 \mathrm{~J}$ background. Antisera to Gs $\alpha$ recognizes 52 and $45 \mathrm{kDa}$ forms of the protein (top panel). The 52 and $45 \mathrm{kDa}$ signals were summed for densitometric analysis (middle panel). The filter was stripped and reprobed with Go $\alpha$ antisera for normalization of Gs $\alpha$ levels. Go $\alpha$ levels did not differ by genotype. Each lane represents membranes from one mouse (40 $\mu \mathrm{g} /$ lane). AlF- and GTP-stimulated adenylyl cyclase activity in nucleus accumbens membranes $(* p<0.05)$ (bottom panel).

Table 1. Adenylyl cyclase activity in mice carrying the Gnas (-/+)

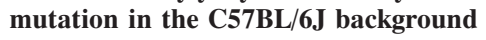

\begin{tabular}{lcc} 
Brain region & C57BL/6J $(+/+)$ & C57BL/6J $(-/+)$ \\
\hline Hypothalamus & $2268 \pm 142$ & $1748 \pm 107^{*}$ \\
Cerebellum & $2182 \pm 195$ & $1682 \pm 97^{*}$ \\
Hippocampus & $673 \pm 50$ & $520 \pm 25^{*}$ \\
Frontal cortex & $1566 \pm 118$ & $1230 \pm 173^{*}$ \\
Brainstem & $1179 \pm 61$ & $942 \pm 77^{*}$
\end{tabular}

$(+/+)$, Wild type; $(-/+)$, Gnas.

${ }^{*} p<0.05 ; n=5-7$ per group. Units, picomoles per milligram protein per $20 \mathrm{~min}$.

(35\% reduction), frontal cortex (22\% reduction), and brainstem ( $21 \%$ reduction).

We next determined whether the sedative effects of ethanol are altered in Gnas $(-/+)$ mice because of the potential role of cAMP-PKA signaling in this effect (Froehlich and Wand, 1997). Gnas $(-/+)$ mice were more sensitive to the sedative effects of ethanol, taking twice as long to regain their righting reflex as WT littermates (Fig. 2a). Differences in sensitivity were not caused by differences in acute clearance of ethanol, because plasma ethanol concentrations did not differ between genotypes (Fig. 2b). 

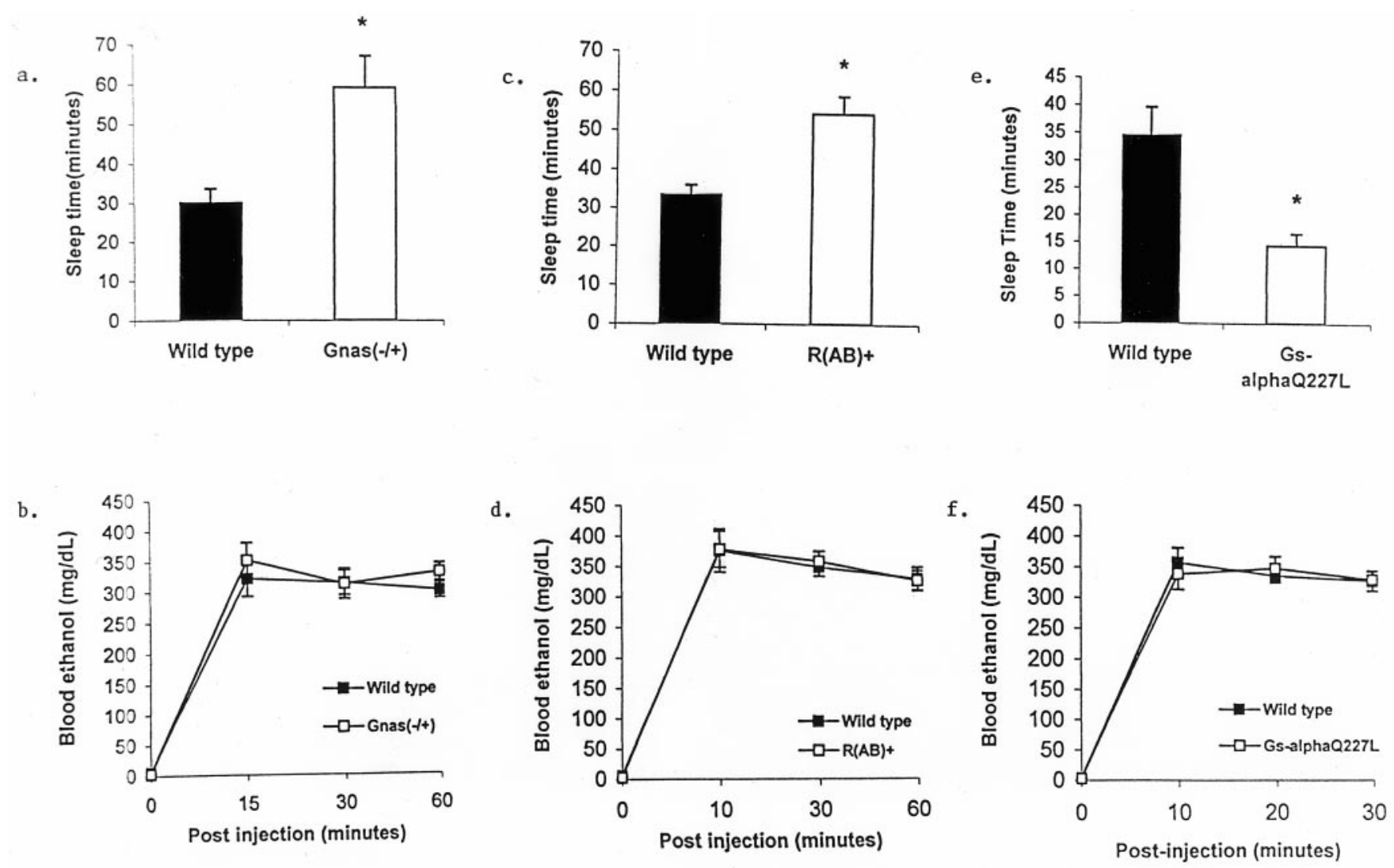

Figure 2. Sleep time as a measurement of sensitivity to the sedative hypnotic effects of ethanol $(3.5 \mathrm{~g} / \mathrm{kg}) . a$, Gnas $(-/+)$ versus wild-type, ${ }^{*} p<0.001$. $c$, $\mathrm{R}(\mathrm{AB})$ versus wild-type, ${ }^{*} p<0.001$. $e$, Q227L versus wild-type, ${ }^{*} p<0.001 . b, d, f$, Blood ethanol concentrations at the indicated time points $(n=$ $6-12$ per genotype). Values are mean \pm SEM.

To test ethanol consumption, mice were given $24 \mathrm{hr}$ access to two feeding tubes, one containing water, and the other $3 \%$ ethanol. The concentration of ethanol was then increased to 6,10 , and $20 \%$ ethanol every $3 \mathrm{~d}$ for further trials. Gnas $(-/+)$ mice consumed only $40-50 \%$ as much ethanol as WT mice (Fig. $3 a-c$ ). When consumption of ethanol is expressed relative to total fluid consumption (ethanol-preference ratio), Gnas $(-/+)$ mice showed a lower intake of ethanol and preferred water to ethanol (preference ratio, $<0.5$ ) during access to 6,10 , and $20 \%$ ethanol solutions. By contrast, WT mice consistently preferred ethanol to water across all ethanol concentrations $<20 \%$. There were no significant differences between genotypes in measures of average total fluid consumption (water plus ethanol, in milliliters) (Fig. 3d).

To determine whether these differences might reflect a more global change in taste preferences, we tested Gnas (-/+) and WT mice with sucrose and quinine solutions, using the same protocol as above. There were no significant differences between genotypes in preference for the sweet and bitter compounds, relative to water (Fig. 3e,f). Decreased preference for ethanol by mice with reduced Gs $\alpha$ expression did not generalize to other flavored solutions. Furthermore, there were no significant differences between genotypes in measures of average food intake (Fig. $4 g$ ) or body weight (Fig. $3 h$ ). Thus, the targeted disruption of one Gnas allele with resultant decreases in Gs $\alpha$ protein expression and adenylyl cyclase activity converted ethanol-preferring mice into ethanol nonpreferring mice.

To be more certain that inactivation of one Gnas allele was responsible for decreased preference for ethanol and increased sensitivity to the sedative effect of ethanol, we studied the effects of Gnas $(-/+)$ carried in two other genetic backgrounds: 129/ SvEv and CD1X129/SvEv. Regardless of genetic background, Gnas $(-/+)$ mice have increased sensitivity to the sedative effects of ethanol (Table 2) and decreased alcohol preference (Table 3) compared with their WT littermates.

Gs $\alpha$ modulates all known isoforms of adenylyl cyclase as well as L-type calcium channels (Blumenstein et al., 1999). To determine if the cAMP-PKA signaling pathway distal to cAMP generation plays a role in ethanol consumption and ethanol-induced sedation, we studied transgenic mice that express $\mathrm{R}(\mathrm{AB})$, a dominant inhibitor isoform of the regulatory subunit of PKA in neurons of the forebrain under the control of CaMKII $\alpha$ gene promoter (Abel et al., 1997). These mice have reduced PKA activity limited to the hippocampus and forebrain regions but normal activity within the cerebellum, brainstem, hypothalamus, and other brain regions (Abel et al., 1997). Similar to Gnas (+/-), $\mathrm{R}(\mathrm{AB})$ mice were more sensitive to ethanol-induced sedation than WT littermates (Fig. $2 c, d$ ). Increased sensitivity to sedation in $\mathrm{R}(\mathrm{AB})$ mice was not accompanied by increased numbers of $\mathrm{GABA}_{\mathrm{A}}$ receptors or receptor affinity (data not shown). Moreover, $\mathrm{R}(\mathrm{AB})$ mice drank significantly less ethanol at all the concentrations tested (Fig. $4 a-c$ ) and had a lower preference for ethanol compared with WT littermates. Because of the restricted expression pattern of the $\mathrm{R}(\mathrm{AB})$ transgene, the data argue PKA acts within the hippocampus, cortex, striatum, or nucleus accumbens to modulate these effects of ethanol.

To further elucidate the relationship between Gs $\alpha$ expression and ethanol, we examined transgenic mice that express a consti- 


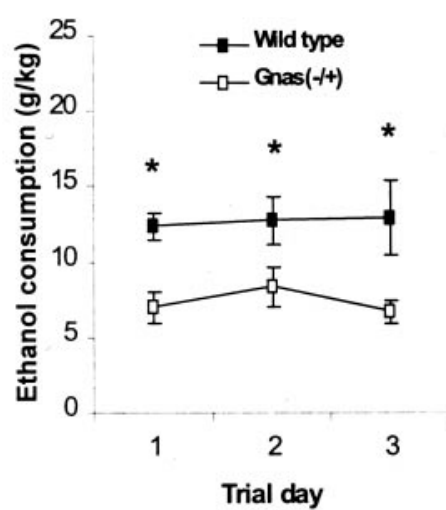

a.

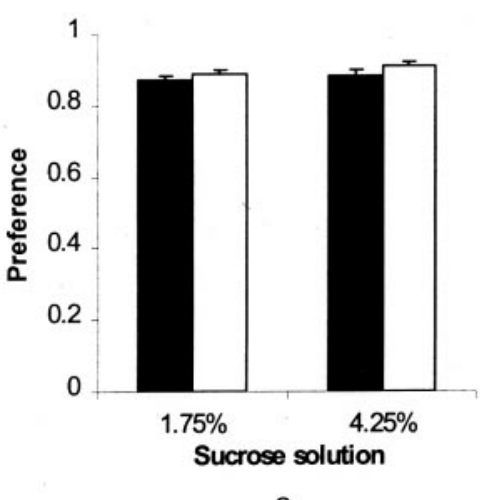

e.

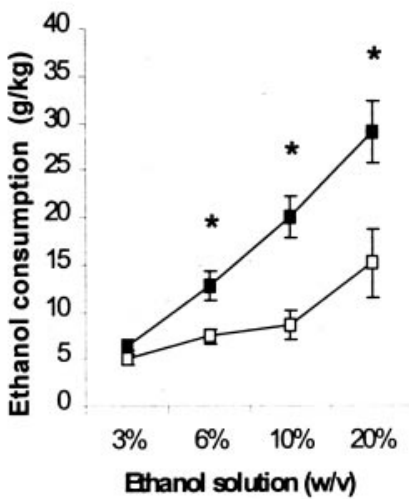

b.

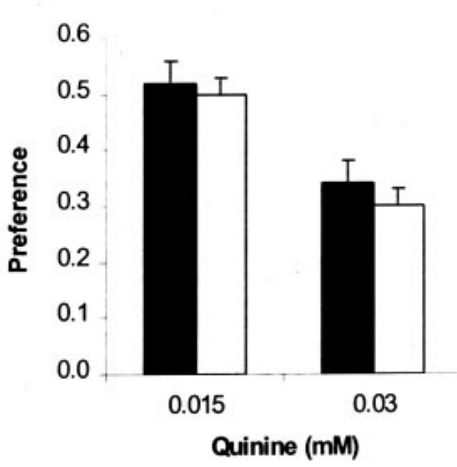

f.

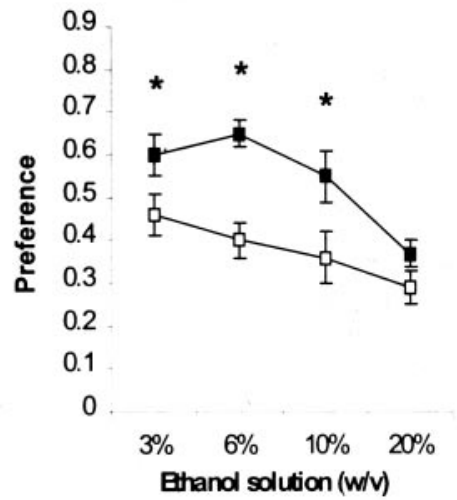

c.

5

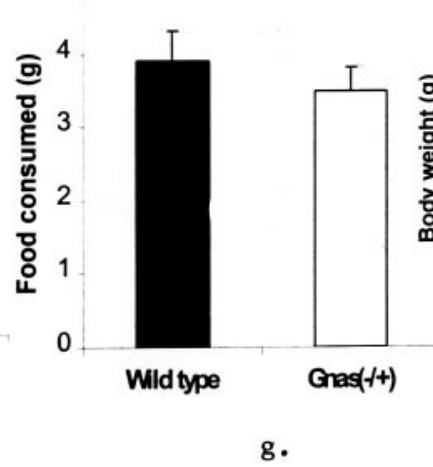

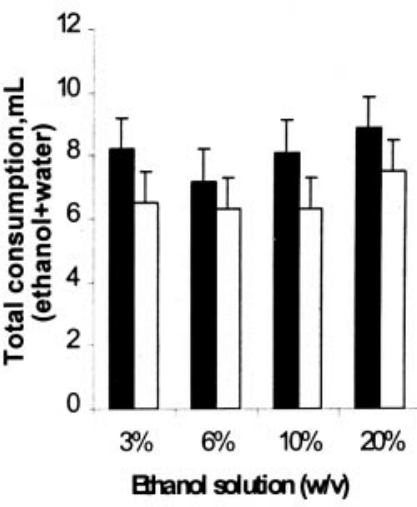

d.

Figure 3. Consumption of ethanol by Gnas $(-/+)$ mice and wild-type littermates in C57BL/6J background. $a$, Consumption (in grams per kilogram) of $6 \%$ ethanol solution (genotype, $F_{(1,14)}=7.28, p=0.019$ ). $b$, Consumption (in grams per kilogram per day) of each ethanol solution, $3 \mathrm{~d}$ average, (genotype, $\left.F_{(1,14)}=19.37, p=0.001\right)$. $c$, Ethanol-preference ratios (volume of ethanol consumed per total volume of fluid consumed) as a measure of relative ethanol preference (genotype, $F_{(1,14)}=27.48, p=0.0001$ ). $d$, Total fluid consumption (ethanol plus water, in milliliters). $e, f$, Preference ratios for sucrose and quinine (volume of solution consumed per total volume of fluid consumed). $g, h$, Average total food intake per day over trial period and average body weight at the start of trials. Values are mean \pm SEM $(n=6$ per genotype and concentration). Groups were compared by two-way repeated measures ANOVAs. ${ }^{*} p<0.05$ relative to wild-type littermates, post hoc Tukey.

tutively active form of $\mathrm{Gs} \alpha(\mathrm{Gs} \alpha \mathrm{Q} 227 \mathrm{~L})$ in neurons limited to the hippocampus, neocortex, striatum, and amygdala under the control of the CaMKII $\alpha$ promoter (Fig. 5). This mutant form of Gs $\alpha$ is constitutively active because of its reduced GTPase activity resulting in increased adenylyl cyclase activity (Landis et al., 1989). We found twofold to threefold increases in basal adenylyl cyclase activity in membranes derived from hippocampus, nucleus accumbens, and frontal cortex of transgenic mice compared with wild type (Table 4). No genotype differences were observed in membranes derived from cerebellum, a region where the transgene is not expressed.

In contrast to Gnas $(-/+)$ and $\mathrm{R}(\mathrm{AB})$ mice, Gs $\alpha \mathrm{Q} 227 \mathrm{~L}$ transgenic mice, which exhibit increased adenylyl cyclase activity, were markedly less sensitive to ethanol-induced sedation compared with WT littermates (Fig. 2e,f). However, transgenic mice had similar ethanol consumption and preference scores compared with WT mice (Fig. 6).

\section{DISCUSSION}

Our studies show that reduced signaling through the cAMP-PKA system in the brain, whether because of decreased expression of Gs $\alpha$ or inhibition of PKA, changed an ethanol-preferring line of mice $(\mathrm{C} 57 \mathrm{BL} / 6 \mathrm{~J})$ into ethanol nonpreferring rodents. In Gnas $(-/+)$ mice, this phenotype was maintained when the genetic background was varied. Thus, the cAMP-PKA signal transduction pathway is critical in modulating ethanol intake. However, it is important to note that upregulation of cAMP-PKA signaling, through use of the Gs $\alpha$ Q227L transgene, did not increase ethanol consumption. The inability to find a difference in alcohol preference in Gs $\alpha$ Q227L transgenic mice and WT may reflect that C57BL/J6 mice are an alcohol-preferring line and already exhibit exceedingly high alcohol preference. We speculate there is a ceiling effect. Placement of the transgene in a mouse line that is not alcohol-preferring will determine if transgene expression can create an alcohol-preferring mouse. However, there may be a more complex relationship between the sedative and rewarding effects of alcohol than previously suspected.

Our data provides the first demonstration that the upregulation and downregulation of the cAMP-PKA signaling produces opposite phenotypes vis-à-vis sedative effects of alcohol in mammals. Furthermore, expression of the $\mathrm{R}(\mathrm{AB})$ and Gs $\alpha \mathrm{Q} 227 \mathrm{~L}$ transgene is limited to the forebrain, striatum, and hippocampus. The transgenes are not expressed in the cerebellum or hypothalamus (or any other brain regions), which have always been proposed sites for ethanol-induced sedation. Thus, our data are the first to rule out specific brain regions as being important for both alcohol-induced sedation and alcohol preference mediated by 


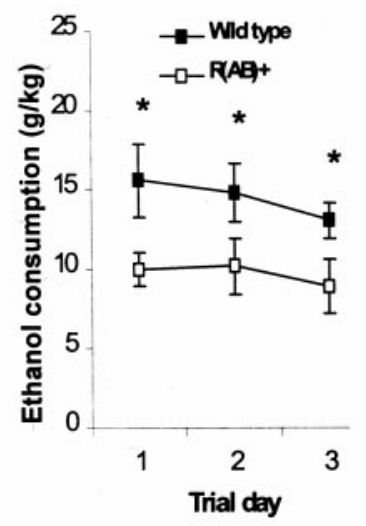

a.

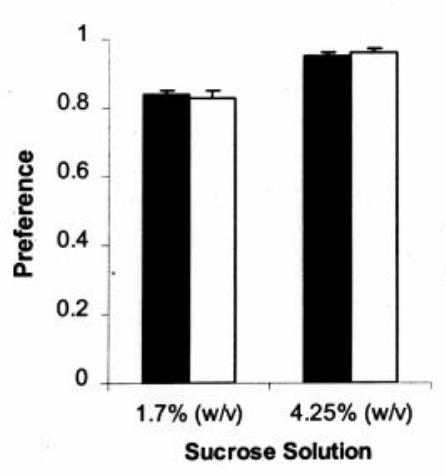

e.

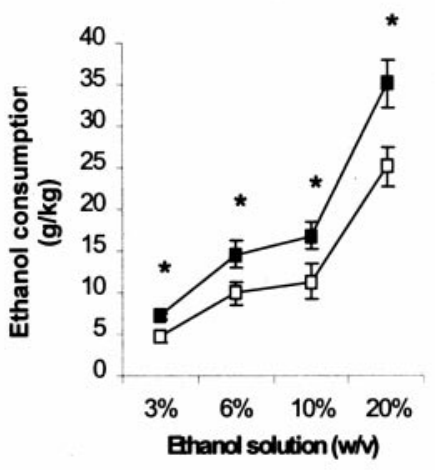

b.

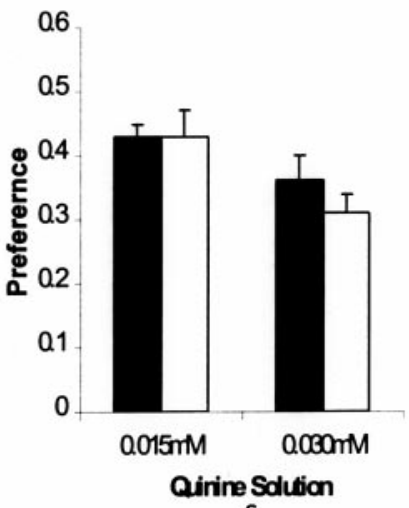

$f$.

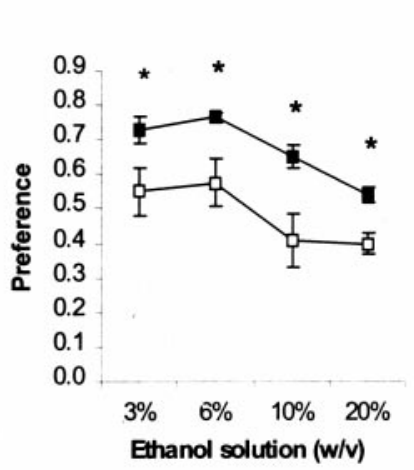

c.

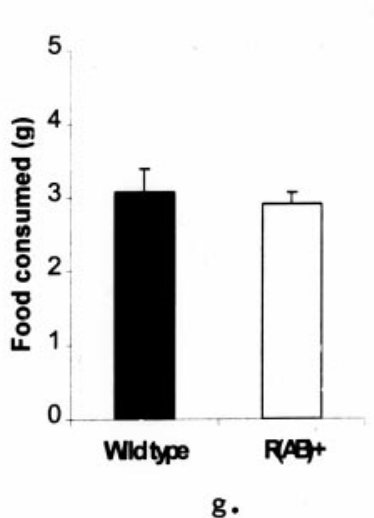

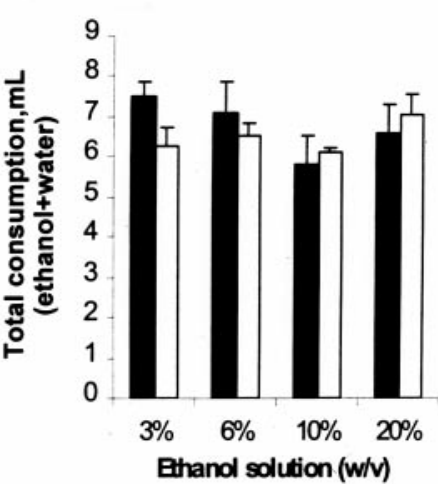

d.

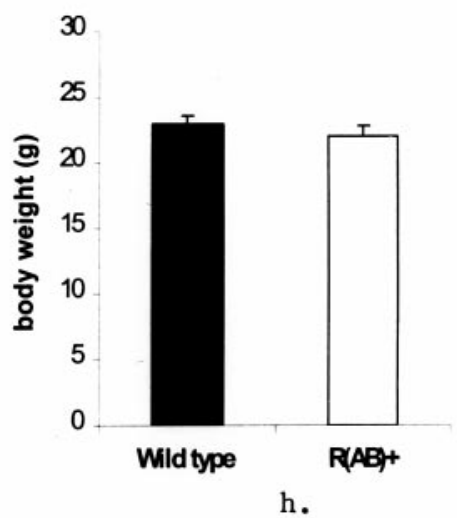

Figure 4. Consumption of ethanol by $\mathrm{R}(\mathrm{AB})$ mice and wild-type littermates in C57BL/6J background. $a$, Consumption (in grams per kilogram) of $6 \%$ ethanol solution (genotype, $F_{(1,12)}=6.0, p=0.034$ ). $b$, Consumption (in grams per kilogram per day) of each ethanol solution, $3 \mathrm{~d}$ average (genotype, $\left.F_{(1,12)}=12.17, p=0.006\right) . c$, Ethanol-preference ratios (volume of ethanol consumed per total volume of fluid consumed) as a measure of relative ethanol preference (genotype, $F_{(1,12)}=20.55, p=0.001$ ). $d$, Total fluid consumption (ethanol plus water, in milliliters). $e, f$, Preference ratios for sucrose and quinine (volume of solution consumed per total volume of fluid consumed). $g, h$, Average total food intake per day over trial period and average body weight at the start of trials. Values are mean \pm SEM $(n=6$ per genotype and concentration). Groups were compared by two-way repeated measures ANOVAs. ${ }^{*} p<0.05$ relative to wild-type littermates, post hoc Tukey test.

Table 2. Sleep time responses to ethanol in mice carrying the Gnas (-/+) mutation in two backgrounds

\begin{tabular}{lllcc} 
Background & $129 \times \mathrm{CD}-1(+/+)$ & $129 \times \mathrm{CD}-1(-/+)$ & $129(+/+)$ & $129(-/+)$ \\
\hline Sleep time $(\min )$ & $10 \pm 2$ & $23 \pm 6^{*}$ & $87 \pm 12$ & $151 \pm 4^{*}$ \\
Sample size & $n=9$ & $n=7$ & $n=6$ & $n=5$
\end{tabular}

$(+/+)$, wild type; $(-/+)$, Gnas.

${ }^{*} p<0.05$.

Table 3. Ethanol (6\%) preference in mice carrying the Gnas $(-/+)$ mutation in two backgrounds

\begin{tabular}{lcccc} 
Background & $129 \times \mathrm{CD}-1(+/+)$ & $129 \times \mathrm{CD}-1(-/+)$ & $129(+/+)$ & $129(-/+)$ \\
\hline Preference & $0.29 \pm 0.2$ & $0.20 \pm 0.1^{*}$ & $0.27 \pm 0.05$ & $0.19 \pm 0.01^{*}$ \\
Total fluid (ml) & $9.9 \pm 0.9$ & $8.4 \pm 0.8$ & $7.3 \pm 0.4$ & $6.2 \pm 0.2$ \\
Weight $(\mathrm{gm})$ & $29 \pm 1$ & $27 \pm 2$ & $26 \pm 1$ & $22 \pm 1$ \\
Food $(\mathrm{gm} / \mathrm{d})$ & $4.5 \pm 0.3$ & $4.3 \pm 0.2$ & $4.9 \pm 0.9$ & $4.7 \pm 0.4$ \\
Sample size & $n=12$ & $n=7$ & $n=5$ & $n=5$
\end{tabular}

$(+/+)$, wild type; $(-/+)$, Gnas.

${ }^{*} p<0.05$.

cAMP-PKA signaling. Moreover, the CaMKII $\alpha$ promoter is not expressed prenatally, indicating that our observations are not the product of developmental alterations induced by prenatal transgene expression.

The role of cAMP-PKA system in mediating sedative or hypnotic effects of ethanol extends to invertebrates as well. In Drosophila inactivation of the amnesiac gene, which encodes a secreted neuropeptide that induces cAMP production, as well as mutations in rutabaga, a calcium-sensitive isoform of adenylyl cyclase, makes flies more sensitive to ethanol-induced sedation 

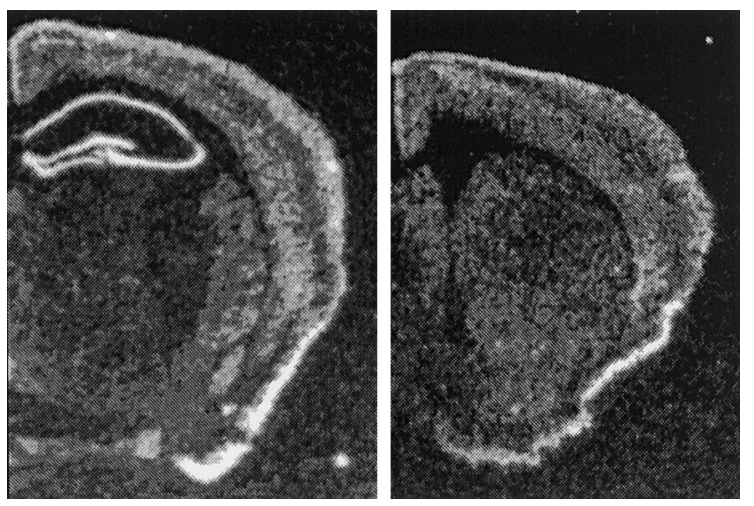

Figure 5. Regional distribution of Gs $\alpha \mathrm{Q} 227 \mathrm{~L}$ transgene. To determine the distribution of transgene expression in the brain, we performed in situ hybridization studies using a transgene-specific oligonucleotide as described (Abel et al., 1997b). In coronal sections taken from a Gs $\alpha$ Q227L transgenic mouse, expression of the transgene can be observed in the cortex and striatum (rostral section, left) and in the hippocampus (caudal section, right). No transgene expression is observed in the cerebellum, hypothalamus, thalamus, or brainstem. No expression is seen in wild-type control animals (data not shown).

Table 4. Basal adenylyl cyclase activity in Gs $\alpha(\mathrm{Q} 227 \mathrm{~L})$ mice and WT littermates

\begin{tabular}{lcc} 
Brain region & WT & Gs $\alpha(\mathrm{Q} 227 \mathrm{~L})$ \\
\hline Nucleus accumbens & $298 \pm 48$ & $1152 \pm 281^{*}$ \\
Cerebellum & $41 \pm 8$ & $67 \pm 15$ \\
Hippocampus & $90 \pm 10$ & $193 \pm 7^{*}$ \\
Frontal cortex & $36 \pm 14$ & $86 \pm 7^{*}$ \\
\hline
\end{tabular}

${ }^{*} p<0.05 ; n=3-4$ per group.

(Moore et al., 1998). Findings from $\mathrm{R}(\mathrm{AB})$ mice support the notion that events distal to $\mathrm{CAMP}$ are important in mediating the observed differences in sensitivity to ethanol.

One mechanism by which the absence or reduction in PKA could enhance ethanol-induced sedation is by increasing the number of $\mathrm{GABA}_{\mathrm{A}}$ receptors. However, we did not find increased $\mathrm{GABA}_{\mathrm{A}}$ receptor number or affinity in $\mathrm{R}(\mathrm{AB})$ mice. Alternatively, it is known that GABA-induced chloride currents are dampened by PKA-induced phosphorylation of specific GABA receptor subunits (Leidenheimer et al., 1991; Whiting et al., 1999). Therefore, it is possible that Gnas $(-/+)$ and $\mathrm{R}(\mathrm{AB})$ mice with low adenylyl cyclase and PKA activity may be more sensitive to the sedative effects of alcohol because of reduced phosphorylation of GABA receptors, resulting in a greater chloride flux compared with wild-type mice. In contrast, Gs $\alpha$ Q227L mice with constitutively active Gs $\alpha$ may be less sensitive to the hypnotic effects of alcohol because of enhanced PKA-induced phosphorylation GABA receptors, resulting in a dampening of chloride currents. Overall, our observations fit well with the widely held assumption that persons at increased risk for alcoholism are less sensitive to the sedative and hypnotic properties of ethanol (Schuckit, 2000).

In summary, our results show that cAMP-PKA signal transduction modulates ethanol intake and sensitivity to sedative effects of ethanol, and they may help explain the observations from several other studies. For example, both the 5-HT $\mathrm{HB}_{1 \mathrm{~B}}$ receptor (Zgombick and Branchek, 1998) and neuropeptide Y (Thiele et al., 1998) inhibit adenylyl cyclase activity. 5-HT $1 \mathrm{~B}$ receptordeficient as well as neuropeptide Y-deficient mice have increased a.

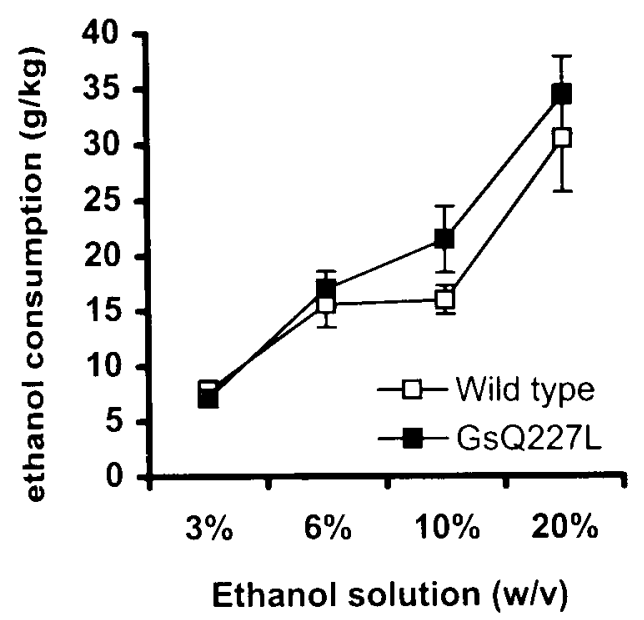

b.

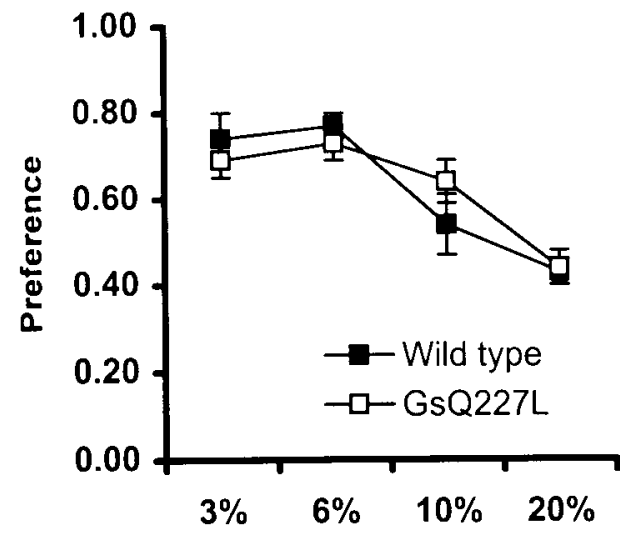

Ethanol solution (w/v)

Figure 6. Consumption of ethanol by Gs $\alpha$ Q227L transgenic mice and wild-type littermates in C57BL/6J background. $a$, Consumption (in grams per kilogram per day) of each ethanol solution, $3 \mathrm{~d}$ average. $b$, Ethanolpreference ratios [volume of ethanol consumed (in milliliters) per total volume of fluid consumed (in milliliters)]) as a measure of relative ethanol preference.

alcohol consumption and reduced sensitivity to alcohol (Crabbe et al., 1996; Navarro et al., 2000). In contrast, neuropeptide Y overexpressing mice have the opposite phenotype (Thiele et al., 1998). Moreover, RII $^{\beta}$ knock-out mice, which are speculated to have chronically unregulated catalytic units of PKA, also have increased alcohol intake and reduced sensitivity to alcohol (Thiele et al., 2000). Alcoholism is a polygenic disorder with genetic and environmental determinants. We speculate that persons at increased risk for alcoholism may carry one or more functional polymorphisms affecting the neurotransmitters, receptors, and other proteins responsible for maintaining integrity of the cAMP-PKA signaling within the forebrain and mesolimbic system.

\section{REFERENCES}

Abel T, Kandel E (1998) Positive and negative regulatory mechanisms that mediate long-term memory storage. Brain Res Brain Res Rev 26:360-378.

Abel T, Nguyen PV, Barad M, Deuel TA, Kandel ER, Bourtchouladze R (1997) Genetic demonstration of a role for PKA in the late phase of LTP and in hippocampus-based long-term memory. Cell 88:615-626. Abel T, Martin KC, Bartsch D, Kandel ER (1998) Memory suppressor 
genes: inhibitory constraints on the storage of long-term memory. Science 279:338-341.

Blumenstein Y, Ivanina T, Shistik E, Bossi E, Peres A, Dascal N (1999) Regulation of cardiac L-type $\mathrm{Ca}^{2+}$ channel by coexpression of $\mathrm{G}$ (alpha s) in Xenopus oocytes. FEBS Lett 444:78-84.

Crabbe JC, Phillips TJ, Feller DJ, Hen R, Wenger CD, Lessov CN, Schafer GL (1996) Elevated alcohol consumption in null mutant mice lacking 5-HT1B serotonin receptors. Nat Genet 14:98-101.

Devor EJ, Cloninger CR, Hoffman PL, Tabakoff B (1991) A genetic study of platelet adenylate cyclase activity: evidence for a single major locus effect in fluoride-stimulated activity. Am J Hum Genet 49:372-377.

Foroud T, Li TK (1999) Genetics of alcoholism: a review of recent studies in human and animal models. Am J Addict 8:261-278.

Froehlich JC, Wand GS (1997) Adenylyl cyclase signal transduction and alcohol-induced sedation. Pharmacol Biochem Behav 58:1021-1030.

Gordon AS, Krauss SW, Nagy L, Diamond I (1991) Nucleoside transport in lymphocytes from alcoholics and non-alcoholics. Adv Exp Med Biol 309A:387-390.

Hayward BE, Kamiya M, Strain L, Moran V, Campbell R, Hayashizaki Y, Bonthron DT (1998) The human GNAS1 gene is imprinted and encodes distinct paternally and biallelically expressed $\mathrm{G}$ proteins. Proc Natl Acad Sci USA 95:10038-10043.

Hodge CW, Mehmert KK, Kelley SP, McMahon T, Haywood A, Olive MF, Wang D, Sanchez-Perez AM, Messing RO (1999) Supersensitivity to allosteric GABA(A) receptor modulators and alcohol in mice lacking PKCepsilon. Nat Neurosci 2:997-1002.

Hoffman PL, Tabakoff B (1990) Ethanol and guanine nucleotide binding proteins: a selective interaction. FASEB J 4:2612-2622.

Landis CA, Masters SB, Spada A, Pace AM, Bourne HR, Vallar L (1989) GTPase inhibiting mutations activate the alpha chain of Gs and stimulate adenylyl cyclase in human pituitary tumours. Nature 340:692-696.

Leidenheimer NJ, Machu TK, Endo S, Olsen RW, Harris RA, Browning MD (1991) Cyclic AMP-dependent protein kinase decreases gammaaminobutyric acidA receptor-mediated $36 \mathrm{Cl}$ - uptake by brain microsacs. J Neurochem 57:722-725.

Menninger JA, Baron AE, Tabakoff B (1998) Effects of abstinence and family history for alcoholism on platelet adenylyl cyclase activity. Alcohol Clin Exp Res 22:1955-1961.

Moore MS, DeZazzo J, Luk AY, Tully T, Singh CM, Heberlein U (1998) Ethanol intoxication in Drosophila: genetic and pharmacological evidence for regulation by the cAMP signaling pathway. Cell 93:997-1007.

Navarro M, Spray KJ, Cubero I, Thiele TE, Bernstein IL (2000) cFos induction during conditioned taste aversion expression varies with aversion strength. Brain Res 887:450-453.

Parsian A, Todd RD, Cloninger CR, Hoffman PL, Ovchinnikova L, Ikeda H, Tabakoff B (1996) Platelet adenylyl cyclase activity in alcoholics and subtypes of alcoholics. WHO/ISBR A Study Clinical Centers Alcohol Clin Exp Res 20:745-751.

Schuckit MA (1994) The 1994 Isaacson Award Lecture: a prospective study of sons of alcoholics. Alcohol Alcohol [Suppl] 2:1-6.

Schuckit MA (2000) Genetics of the risk for alcoholism. Am J Addict 9:103-112.

Schwindinger WF, Reese KJ, Lawler AM, Gearhart JD, Levine MA (1997) Targeted disruption of Gnas in embryonic stem cells. Endocrinology 138:4058-4063.

Self DW, Genova LM, Hope BT, Barnhart WJ, Spencer JJ, Nestler EJ (1998) Involvement of cAMP-dependent protein kinase in the nucleus accumbens in cocaine self-administration and relapse of cocaineseeking behavior. J Neurosci 18:1848-1859.

Spanagel R, Weiss F (1999) The dopamine hypothesis of reward: past and current status. Trends Neurosci 22:521-527.

Tabakoff B, Hoffman PL, Lee JM, Saito T, Willard B, Leon-Jones F (1988) Differences in platelet enzyme activity between alcoholics and nonalcoholics. N Engl J Med 318:134-139.

Thiele TE, Marsh DJ, Marie L, Bernstein IL, Palmiter RD (1998) Ethanol consumption and resistance are inversely related to neuropeptide Y levels. Nature 396:366-369.

Thiele TE, Willis B, Stadler J, Reynolds JG, Bernstein IL, McKnight GS (2000) High ethanol consumption and low sensitivity to ethanolinduced sedation in protein kinase A-mutant mice. $\mathrm{J}$ Neurosci 20:RC75(1-6).

Waltman C, Levine MA, McCaul ME, Svikis DS, Wand GS (1993) Enhanced expression of the inhibitory protein $\mathrm{Gi} 2$ alpha and decreased activity of adenylyl cyclase in lymphocytes of abstinent alcoholics. Alcohol Clin Exp Res 17:315-320.

Wand GS, Waltman C, Martin CS, McCaul ME, Levine MA, Wolfgang D (1994) Differential expression of guanosine triphosphate binding proteins in men at high and low risk for the future development of alcoholism. J Clin Invest 94:1004-1011.

Whiting PJ, Bonnert TP, McKernan RM, Farrar S, le Bourdelles B, Heavens RP, Smith DW, Hewson L, Rigby MR, Sirinathsinghji DJ, Thompson SA, Wafford KA (1999) Molecular and functional diversity of the expanding GABA-A receptor gene family. Ann NY Acad Sci 868:645-653.

Zgombick JM, Branchek TA (1998) Native 5-HT1B receptors expressed in OK cells display dual coupling to elevation of intracellular calcium concentrations and inhibition of adenylate cyclase. Naunyn Schmiedebergs Arch Pharmacol 358:503-508. 